\title{
As "origens" dos Maracatus-Nação do Recife: uma história linear e sem transformações?
}

\begin{abstract}
Resumo
O presente texto objetiva discutir as perspectivas assumidas por alguns estudiosos dos maracatus-nação que estabeleceram suas origens como resultantes da coroação dos reis e rainhas do Congo. Na sequência, o artigo versa sobre a influência do conceito de tradição em trabalhos de diferentes autores dedicados ao tema e à construção da representação dos maracatus-nação baseada na ideia de estabilidade, ou seja, de ausência de mudanças na manifestação cultural. Para concluir, a análise mostra outras manifestações culturais assemelhadas e a maneira como estas sugerem outras dinâmicas no processo de constituição das práticas e costumes culturais.
\end{abstract}

Palavras-chave: Maracatu-Nação. Práticas Culturais. Cambindas. Congos. Aruendas. Pretinhas do Congo.
Ivaldo Marciano França Lima

Doutor em História pela Universidade Federal Fluminense (UFF). Professor na Universidade do Estado da Bahia (UNEB - DEDC II/Alagoinhas - BA). Coordenador do Programa de PósGraduação em Estudos Africanos e Representações da África. Membro permanente do Programa de Pós-Graduação em Difusão do Conhecimento (DMMDC).

Alagoinhas, BA - BRASIL

ivaldomarciano@gmail.com orcid.org/0000-0001-6592-6056

\section{Para citar este artigo:}

LIMA, Ivaldo Marciano de França. As “origens” dos Maracatus-Nação do Recife: uma história linear e sem transformações? Tempo e Argumento, Florianópolis, v. 11, n. 27 , p. 255 - 282, maio/ago. 2019. 


\title{
The "origins" of the \\ Maracatus-Nation of Recife: a linear and untransformed history?
}

\begin{abstract}
The present text aims to discuss the perspectives assumed by some maracatus-nation scholars who established their origins as a result of the coronation of Congo kings and queens. The article deals with the influence of the concept of tradition in the works of different authors dedicated to the theme and the construction of the representation of the maracatus-nation based on the idea of stability, in other words, of the absence of changes in the cultural manifestation. To conclude, the analysis shows other similar cultural manifestations and the way in which they suggest other dynamics in the process of constitution of cultural practices and customs.
\end{abstract}

Keywords: Maracatu-Nation. Cultural Practices.

Cambindas. Pretinhas do Congo. Aruendas.

Pode-se pensar nos maracatus-nação enquanto práticas culturais advindas de um tempo imemorial, constituído por saberes transmitidos de forma oral, baseados numa tradição repetida de pai para filho, com formato imutável, estático, sem que mudanças Ihe tenham sido atribuídas ao longo dos anos? Há como imaginar um maracatu que não seja formado por homens e mulheres, e que não seja integrado por rostos, com cores, cheiros, gestos, nomes, intenções e sentidos? Ora, tais representações não se constituem em algo minimamente sensato, ainda mais quando se sabe que uma prática cultural possui o fazer e o refazer como marca registrada. Logo, jamais poderia ser mantida incólume e isenta de mudanças ao longo dos tempos. Contudo, muitos autores que se 
dispuseram a pensar o maracatu como fenômeno, lhe atribuíram representações diversas, das quais, a de que se tratava de uma manifestação estável, sem transformações profundas e dotado de uma perspectiva de ter sido originado de forma linear. Seria isso possível? ${ }^{1}$

O maracatu-nação pode ser definido como uma manifestação cultural dotada de elementos diversos. Dispõe de dança, canto, fantasias e estilo musical próprio. Uma melhor definição pode ser tomada pelo aspecto de que a palavra 'maracatu' serve tanto para nomear a música feita por essa manifestação, bem como para a dança e o cortejo propriamente dito. Por falar na música, esta é cantada por um homem, denominado genericamente como mestre. Ele é acompanhado dos batuqueiros, que tocam afayas (os tambores), caixas, taróis, mineiros (espécie de ganzá) e gonguês (instrumento de ferro com uma campânula, percutida por um pedaço de madeira) (LIMA, 2014).

Nos dias atuais, há mulheres tocando instrumentos, bem como ocupando o lugar de mestre, algo impensável para épocas mais recuadas no tempo. Existem maracatusnação que possuem fortes ligações com as religiões de terreiro, a exemplo da religião dos orixás (xangô - PE; candomblé - BA; batuque - RS), e há até bem pouco tempo, houve quem afirmasse serem eles simples extensões carnavalescas destas. No entanto, a relação dos maracatus-nação com o sagrado não se resume aos orixás, pois há grupos em que a jurema e a umbanda também estão presentes (LIMA, 2008). ${ }^{2}$

Ao longo dos anos, os maracatus foram representados como dotados de uma origem possível de ser identificada, ora como uma prática trazida do continente africano (sob a compreensão de uma África indistinta), ora como "herança africana", resultado "dos tempos antigos da escravidão" e das festas de coroação dos reis e rainhas do Congo. Essa questão nos remete, de forma inelutável, às representações construídas por alguns folcloristas e memorialistas que se preocuparam com a questão. Estes, por seu turno, consolidaram um percurso intelectual de que toda e qualquer discussão sobre os maracatus-nação deveria começar com a busca por suas origens. Esta seria, como se

\footnotetext{
${ }^{1}$ Por representação, estou tomando os sentidos postos por Chartier (1990; 2002).

2 Sobre a jurema, ver: (VANDEZANDE, 1975; MOTTA, 1997; BRANDÃO, 2001; SALLES, 2004; 2010; ASSUNÇÃO, 2006).
} 
pode observar a partir da análise de parte considerável dos trabalhos destes (folcloristas em especial), de que tal aspecto constituiria a principal maneira para estabelecer a tradução do fenômeno, e o seu devido controle (VILHENA, 1997). Encontrar a origem de algo remeteria, para toda uma geração de folcloristas, o controle sobre a prática, de modo que se pudesse estabelecer seu formato e assim evitar sua "descaracterização" a partir de mudanças “desnecessárias” (ROCHA, 1996).

É preciso, no entanto, marcar a diferença entre os termos “origem" e "origens". Para o primeiro, há uma visão subjacente de que o "início" de algo ocorre a partir de um ponto único, e que é possível perceber o seu nascimento com exatidão, ao contrário do segundo termo, que pressupõe a impossibilidade de tornar preciso o surgimento de algo, principalmente quando se trata de práticas e costumes construídos por seres humanos. Mesmo tomando as assertivas de Cunha (2001) como importantes para admitir que a ideia de "origem" é uma falsa questão para o historiador, o debate entabulado por diferentes estudiosos ao longo da primeira metade do século XX nos assegura ter sido essa uma questão que motivou muitos neurônios a serem condenados, e uma infinidade de cabeças a se indagarem sobre o surgimento de manifestações culturais diversas. Contudo, de fato, a origem é algo impossível de se encontrar, ao contrário das origens, que são indícios, fragmentos ou vestígios do surgimento/existência de alguma coisa. Isso, no entanto, não nos garante possibilidade de demarcar o tempo e o espaço do surgimento de determinada prática cultural, mas, de estabelecer elementos para a feitura de sua genealogia, na acepção discutida por Foucault (1984).

A origem de uma prática é também posta sob o conceito da "tradição", tomandoa por algo que se repete como sobrevivência, posta como tendo se originado num passado remoto. Trata-se de uma operação intelectual que se traduziu em diferentes representações, e que, no caso do maracatu, Ihe atribuiu uma suposta "africanidade", a partir de alguns autores, ou "sobrevivência das festas de coroação dos reis e rainhas do Congo", no dizer de outros 3 . Mesmo que os indícios mostrassem outras possibilidades, a

\footnotetext{
3 Importante observar que o termo "africanidade", ainda hoje usado por muitos autores, remete a uma perspectiva da antropologia evolucionista. Esse conceito também nos leva ao entendimento de que o continente africano pode ser visto como um todo homogêneo, dotado de indistinção no que diz respeito a práticas, costumes, línguas e cultura.
} 
exemplo da diversidade de formatos, os maracatus foram empurrados para uma homogeneidade que não dava conta de diferentes aspectos, sobretudo suas semelhanças com outras práticas culturais ainda hoje existentes ${ }^{4}$. 0 "tradicional" é entendido como algo que possui um vínculo com um passado distante, e que sobrevive em meio aos tempos atuais sob a forma de reminiscência.

Essa preocupação com o passado permeou os trabalhos de diferentes estudiosos, folcloristas e memorialistas que se detiveram na origem dos maracatus-nação, no sentido de Ihes conferir uma autenticidade e, ao mesmo tempo, um vínculo com algo que se encontra permanentemente presente. As tradições, nesse sentido, são entendidas como o resultado da repetição de tempos passados e que "sobrevivem", sem que os seus mantenedores tenham o domínio ou o conhecimento da "origem" (CASCUDO, 2000). Portanto, diante dessa visão de que a tradição perdura imutável ao longo dos tempos, é que um grande número de pesquisadores, estudiosos, folcloristas e memorialistas afirmaram que os maracatus-nação se constituíram numa continuidade ininterrupta das antigas festas de coroação dos reis de Congo. Essa, por sinal, foi a representação construída a partir da famosa descrição de Pereira da Costa, repetida por Real (1990) e outros autores de que os maracatus não sofreram mudanças ao longo dos tempos. Real (1990, p. 59), para justificar a representação de que os maracatus eram dotados de extraordinária estabilidade no tempo, apóia-se na famosa descrição de Costa (1974, p. 215) e mostra o fato de outros autores terem seguido esse caminho, sem grandes questionamentos entre estes.

O que se pode afirmar a partir de uma breve análise dos discursos dos maracatuzeiros da atualidade, é que suas tradições são constantemente atualizadas por seus mantenedores, e que a busca pela origem de determinadas práticas ou costumes, longe de esclarecer, constituiu artifícios que levaram à construção de uma

\footnotetext{
${ }^{4}$ Além da diversidade de tipos de toques e modos de fazer no interior dos maracatus-nação, é possível observar outras manifestações culturais assemelhadas, que possivelmente foram resultado de trocas entre seus praticantes. Cambindas, pretinhas do Congo, congos, maracatus cearenses, maracatus rurais, dentre outros, são alguns dos muitos exemplos possíveis de serem indicados ao leitor para mostrar a extrema diversidade de construções culturais assemelhadas. Sobre a diversidade de estilos no âmbito dos maracatus-nação, ver: LIMA, 2013; 2014. Sobre os maracatus cearenses, ver: SILVA, 2004; MILITÃO, 2007; COSTA, 2009; CRUZ, 2011.
} 
homogeneização daquilo que é diverso, múltiplo ou que simplesmente não existiu como foi descrito. Excelente exemplo dessa homogeneização é a representação construída por diferentes autores (ALMEIDA, 1942; 1971; ANDRADE, 1982; BASTIDE, 1945; COSTA, 1974; PEIXE, 1980; REAL, 1990; 2001; SILVA, 1988a; 1988b; 2002) de que há uma ligação direta entre os maracatus-nação e a instituição da coroação dos reis do Congo. Não sabemos como ocorriam as festas de coroação desses reis com minudência, e sequer podemos discutir as diversidades rítmico-percussivas que nelas existiram. Não há como afirmar que existam vínculos entre os maracatus e essa instituição citada que não sejam permanências, observadas e compreendidas sob a forma de práticas ressignificadas, que ganharam sentidos diferentes nos novos contextos em que foram inseridas. Isso, no entanto, não permite afirmar que tenha havido uma linearidade no que tange a origem, uma vez que essas práticas surgiram em meio a contextos diversos.

\section{Os estudiosos: a construção de uma tradição}

Entre os mais importantes estudiosos que se detiveram sobre a origem dos maracatus-nação, priorizei os trabalhos de Pereira da Costa (1908), Guerra Peixe (1955), Roger Bastide (1958), Katarina Real (1967) e Theo Brandão (1973), principalmente pela repercussão que tiveram para os trabalhos posteriores de outros estudiosos. Esses autores construíram uma visão, ainda hoje hegemônica, de que os maracatus constituem uma "herança" das festas de coroação dos reis do Congo, como se estas fossem um ponto de origem para diversas manifestações culturais existentes no país. No que pesem as diferenças entre esses autores, pode-se afirmar que essas ideias constituem indícios de um tempo em que a história era pensada sob formatos que aludem a uma linearidade, subjacente a uma compreensão da história das práticas numa perspectiva linear.

Pereira da Costa, renomado folclorista que viveu entre os anos de 1851 a 1923 , escreveu sob a influência de que a tradição estava baseada naquilo que sobreviveu de tempos passados e que, por isso, constituía reminiscências (sobrevivências) de algo que existiu. Estava profundamente influenciado, como homem de seu tempo, aos pressupostos da antropologia evolucionista, acreditando que as sociedades eram regidas por estágios civilizatórios (CASTRO, 2005). Ao discutir sobre a provável extinção dos 
maracatus, o autor nos diz que os mesmos estão em processo de desaparecimento, uma vez que "os africanos estavam rareando em nossas terras":

Se o maracatu, prestes a extinguir-se pelo seu arrefecimento, uma vez que não existem mais africanos, e os seus descendentes procuram de preferência imitar a sociedade da gente branca, celebrando as suas festas íntimas com reuniões dançantes segundo os moldes usados; se o maracatu, portanto, já rareando, modestamente aparece somente nas folias carnavalescas, época houve, e bem próxima ainda, em que se exibia em número avultado, mais ou menos bem organizados, ostentando mesmo alguns aparatos, as galas e com um luxo tal que o seu arranjo complexo representava, relativamente, avultada quantia. (COSTA, 1974, p. 216)

A impressão de que as manifestações populares estavam em constante risco de desaparecimento nos revela a existência de um conjunto de ideias que colocava as práticas e os costumes dos homens e mulheres das camadas populares como fruto de uma repetição impensada, e que por isso deveriam existir os especialistas - os folcloristas - que se encarregariam de recolher e registrar aquilo que estivesse correndo risco de desaparecer. Essa visão, subjacente à tese da repetição acrítica, formulada por Cascudo (2000), permite compreender as constantes campanhas de "defesa do folclore" encetadas pelos folcloristas brasileiros, e discutidas por Vilhena (1997). A representação de "iminente desaparecimento" encontra-se subjacente não apenas nos trabalhos de Pereira da Costa, mas também em outros folcloristas que enxergavam os costumes populares em constante risco de desaparecimento. Parafraseando a célebre obra de Gonçalves (2002), as manifestações culturais se encontravam sob o signo da "retórica da perda", e as mudanças operadas nestas eram vistas ora como descaracterizações, ora como fruto do desconhecimento da estrutura e origem da manifestação em questão.

Roger Bastide, que esteve no Brasil como professor da USP entre os anos de 1938 e 1954, encetou questões sobre os maracatus, notadamente suas origens e imagens, que suscitavam representações da África. Em sua passagem pelo Recife em meados dos anos 1940, deparou-se com diversas expressões culturais, e em seu livro, Imagens do Nordeste Místico em branco e preto, escreveu sobre as práticas religiosas do que ele nomeou por “negros pernambucanos" e seus maracatus. Sua interpretação a respeito das origens destes últimos pode ser observada com mais detalhes a partir de suas próprias palavras: 
Ora, e nesse ponto, creio, todo o mundo está de acordo, é preciso procurar a origem desses maracatus na organização das nações no tempo da escravidão, sob a égide das capelas e dos conventos. Já vimos que, sobretudo no interior, as primeiras danças tem lugar diante da porta da igreja e que no Recife o maracatu roda um instante diante de Nossa Senhora do Rosário dos Pretos, como antigamente Davi dançava diante da arca sagrada. (BASTIDE, 1945, p. 180)

No trecho da obra citada, observa-se a relação que o autor constrói entre o catolicismo, que permearia a instituição da coroação dos reis e rainhas do Congo, com os maracatus. Nesse sentido, o autor constrói os liames entre estes últimos com os exercícios de cristianização que foram postos em ação pela colonização portuguesa no Brasil. Bastide concorda com a ideia de que os maracatus são originados das festas de coroação dos reis do Congo e para tanto, discorre sobre essa relação em suas linhas que julgava serem esclarecedoras, reforçando as representações dos maracatus como partes de uma "África encravada em terras brasileiras": (...) Tudo parece explicar-se, dessa maneira. O maracatu é a continuação, até nossos dias, das antigas festas de coroamento dos reis (BASTIDE, 1945, p. 180 - 181). Os maracatus constituem, para Bastide, uma "tradição" que foi originada nas investidas da Igreja sobre os escravos, e deve ser vista como "uma presença africana em terras brasileiras", conforme sua análise nas toadas dos maracatus por ele identificados como "antigos" 5 como o Elefante:

Vê-se que o tema fundamental dessas toadas é a grande viagem de volta, e, com efeito, o maracatu nos leva a fazer essa viagem. Para isso não há necessidade de tomar nenhum navio nem de cruzar o verde mar. 0 próprio maracatu é essa barca (...) Eu também embarquei na galera do Elefante, para essa viagem em direção a uma África irreal... (BASTIDE, 1945, p. 176)

Enfim, para Bastide, os maracatus constituem a "sobrevivência" das coroações dos reis do Congo, e estas devem ser vistas como práticas de natureza cristianizadora, que eram dirigidas aos escravos. O abandono das práticas por parte da Igreja é que explica, segundo o autor, o fato dos maracatus terem se "degradado" a caminho do fetichismo e do carnaval. Sua compreensão para com as práticas e costumes deve ser entendida como de fundamental importância na consolidação de uma representação homogênea do continente africano em nosso país. A metáfora “ilhas de África”, existente

\footnotetext{
${ }^{5}$ Roger Bastide percebeu que existiam diferenças entre os maracatus do Recife, e utilizou-se dos conceitos de "antigos" e "novos" para distingui-los. Mais adiante, iremos discutir essa distinção feita pelo autor.
} 
em um dos seus livros (BASTIDE, 2001), referindo-se aos candomblés baianos como espécie de reservatório e santuário do continente, em sua acepção homogeneizada, no Brasil, justificou e corroborou também com a construção das representações da África em sua dimensão indistinta e, ao mesmo tempo, una. Aliás, observe-se os modos como se refere ao candomblé, nomeando-o como "religião africana", e assim será possível entender os motivos que aludem ao maracatu da forma como o fez.

Outro importante estudioso, e que também se deteve na busca da origem dos maracatus, foi o maestro e musicólogo Guerra Peixe, que realizou suas pesquisas no Recife entre os anos de 1949 a 1952. Em sua famosa obra, Maracatus do Recife, também discutiu as origens dos maracatus e, diante da inexistência de dados mais esclarecedores sobre o assunto, afirma que "O desconhecimento de fontes informativas recuadas no tempo não nos favorece demarcar com exatidão, a época em que teria surgido o maracatu no Recife" (PEIXE, 1980, p. 15).

Guerra Peixe apresenta um quadro com a relação das etapas que existiram até o surgimento dos maracatus no século XX. Vale ressaltar que o referido autor apresenta o antigo governador dos negros, Henrique Dias, como o ponto mais distante no suposto passado dos maracatus (PEIXE, 1980, p.162). Parece-nos que Guerra Peixe buscou a exatidão, o momento do surgimento, deixando claro que sua época não permitia a percepção de que a história, longe de constituir uma linha reta voltada para o futuro, é hoje vista muito mais como uma confluência de escolhas, combinações, acertos, lutas e disputas. Ora, se em algum momento houve a fundação de um maracatu, fato que representaria a origem ou o seu ponto inicial, é possível que ele sequer tenha tido as feições e os formatos que hoje apresenta, por ter sido construído por homens e mulheres que buscam se adaptar no cotidiano aos problemas e dificuldades que se apresentam. Não se pode esquecer que até mesmo as tradições são frutos de um contexto, e como tal, sofrem constantes atualizações, nunca admitidas por aqueles que veem na tradição apenas a repetição ou a permanência do que existiu no passado.

No seu livro, Maracatus do Recife, também é possível perceber, apesar das diferenças, a ideia da tradição baseada na sobrevivência de fragmentos imemoriais do passado. Ao discutir sobre as origens dos maracatus, o autor afirma: 
Os autores modernos concordam que o maracatu seja um cortejo real cujas práticas são reminiscências decorrentes das festas de coroação de reis negros, eleitos e nomeados na instituição do Rei do Congo. (PEIXE, 1980, p. 15)

O que permaneceu é visto como a tradição, possuidora de vínculos diretamente ligados ao passado e, por isso mesmo, detentora do status de "legítima" e "autêntica". Percebemos que é a partir dessa compreensão de tradição que Guerra Peixe e os autores citados discutem a origem dos maracatus, apresentando-os como uma continuidade do passado, pois dessa maneira há a consolidação de certezas da longevidade e da permanência de algo com raízes remotas, mesmo que não seja possível demarcá-las com exatidão.

Outro pensador que se debruçou sobre a origem dos maracatus foi Theo Brandão. Para ele, os maracatus constituem-se como fruto da instituição de coroação dos reis do Congo, mesclado com outras "sobrevivências" "africanas" e "europeias". O autor, em seu texto, publicado em um jornal de grande circulação no Recife, em 1957, afirma que:

É bem verdade que nestas asserções há de se separar aquelas em que se faz derivar o maracatu das festas de coroação dos reis de congos, da outra em que se adianta que tais coroações representam pura tradição africana, sobrevivência de velhos costumes do continente negro. Sobre a primeira parece não restar a mínima dúvida. Todas as descrições do cortejo dos maracatus, a começar na de Pereira da Costa e a terminar na de Ascenço Ferreira, passando por Mário Sette e Roger Bastide, nos fornecem inabalável convicção de que os maracatus derivam dos reinados de congo, isto é, das festas e danças que se realizavam por ocasião do coroamento dos reis de congo. ${ }^{6}$

Neste trecho de um artigo publicado no Diário de Pernambuco, nas vésperas do carnaval que se avizinhava, Theo Brandão procurou mostrar o forte consenso que existia, segundo ele, na ideia de que a origem dos maracatus está na instituição da coroação dos reis do Congo. O consenso é legitimado com a citação de vários estudiosos, entre os quais Pereira da Costa, e a sua recorrente descrição do maracatu Cambinda Velha, que foi citado em quase todos os trabalhos posteriores. Entretanto, Theo Brandão considera que os maracatus não constituem apenas uma tradição advinda da coroação dos reis do

\footnotetext{
${ }^{6}$ BRANDÃO, Theo. Origens do maracatu. Diário de Pernambuco, 07 mar.1957, p. 02 e 08.
} 
Congo, mas também de sobrevivências mais antigas que a própria escravidão: as “reinages europeias”. Tal compreensão é visivelmente percebida nas palavras do autor:

Cabe a Guilherme de Melo a aproximação entre as festas de Congo e os reinados (...) Ora, o reinado - a coroação de reis e rainhas fictícios, é velha tradição européia. O mesmo Guilherme de Melo ligou-o muito justamente a tradição dos reinages de origem francesa, começada em princípios do século XVI (...). ${ }^{7}$

Nesse sentido, os maracatus-nação constituem uma sobrevivência da coroação dos reis do Congo, aliada a antigas reminiscências de origem europeia, longe de serem, portanto, práticas de natureza puramente africana. E esse é outro debate importante sobre a questão, no caso, das supostas origens africanas ou europeias para as práticas culturais em questão. Posições semelhantes às defendidas por Theo Brandão são entabuladas por Basílio de Magalhães (1939; 1944), que nega o fato de ter essa manifestação uma origem puramente "africana". As ideias de "tradição" e de "autenticidade" marcam profundamente o discurso de Theo Brandão, e isso se percebe principalmente quando ele faz a comparação entre os maracatus alagoanos com os de Pernambuco:

Em Alagoas, aliás, nunca alcançaram os maracatus o brilho, a animação e o fausto que ainda hoje perduram nos maracatus pernambucanos, onde sua tradição se mantém viva e brilhante (...) Talvez por que em Alagoas as irmandades de pretos - São Benedito e N. S. do Rosário - nunca tivessem realizado a instituição do Reinado dos Congos, da qual seguramente deriva o maracatu. (BRANDÃO, 1973, p. 162)

Uma questão importante pode ser formulada diante da citação. Ora, se os maracatus são originados da instituição da coroação dos reis do Congo, e se em Alagoas esta não existiu - nas palavras do autor - como surgiram então os grupos do lugar em questão? Na comparação entre os maracatus de Alagoas e Pernambuco, o autor constrói uma distinção entre ambos mostrando que além da origem, há também outra diferença que reside no fato de não serem os primeiros constituídos de "negros autênticos, de ambos os sexos" (BRANDÃO, 1973, p. 162). Em suma, a ideia de tradição enquanto elemento que confere a autenticidade e, por conseguinte, legitimidade, está presente no

\footnotetext{
7 Idem, ibidem, loc cit.
} 
pensamento de Theo Brandão a partir da relação entre a origem e a sobrevivência de fragmentos da mesma.

Katarina Real foi outra importante folclorista que realizou pesquisas sobre o carnaval do Recife, entre os anos de 1961 a 1965. Suas afirmações referentes à origem dos maracatus-nação refletem uma concordância com os vários autores que, antes dela, observaram a relação entre a instituição da coroação dos reis do congo e suas festas com o surgimento dos cortejos já citados (REAL, 1990, p. 55-56). A folclorista aponta em seu livro, O folclore no carnaval do Recife, que “... todos os pesquisadores citados estão de acordo em que estes grupos são, de fato, 'nações' africanas...” (REAL, 1990, p. 56), concordando com a ideia de que os maracatus se constituem de fato como uma sobrevivência das festas de coroação dos reis do Congo.

Katarina Real reforça esse "lugar comum” e aponta a linearidade, construída antes dela, a partir da demonstração do consenso entre os estudiosos que lhe antecederam, e mostra como a ideias de "tradição" e de "autenticidade" estão presentes em suas obras, sobretudo quando distingue os maracatus em nações legítimas e híbridas (REAL, 1990, p. 60). Percebe-se com a questão que, antes de um conceito ingênuo, ou de uma afirmação desprovida de quaisquer intenções que não sejam a de conferir legitimidade para aqueles maracatus ditos "puros", a ideia de tradição em Katarina Real é fortemente influenciada pela relação entre sobrevivência e pureza. Esse aspecto se evidencia, principalmente, quando ela convida, para resolver possíveis problemas que pudessem ocorrer na fundação de um novo maracatu "autêntico", apenas aqueles maracatuzeiros considerados como "os três maiorais das 'nações': 'Seu Luiz', 'Seu Veludinho'e Eudes”. Deste “diálogo" foram excluídos os senhores Tercílio e Zé Gomes, respectivamente articuladores dos maracatus Cambinda Estrela e Indiano (REAL, 2001, p. 54). Essas conclusões, definidoras da prática e comportamento de Katarina Real, expressam as filiações das concepções que norteiam sua ação.

A exclusão dos dirigentes dos maracatus "híbridos", a meu ver, é compreendida a partir da categorização feita pela própria Katarina Real: 
Desses cinco grupos, somente três eram legítimos descendentes das Nações africanas. Os outros dois podiam ser caracterizados de maracatus-nações 'híbridos', porque foram fundados como 'maracatusde-orquestra'e mais tarde modificaram suas estruturas e apresentações carnavalescas. (REAL, 1990, p. 60)

Assim, devem ser observados como aspectos diretamente relacionados, a relação entre a busca pela origem, com a tradição e a legitimidade a serem conferidas aos ditos maracatus "autênticos". Em outras palavras, os maracatus-nação foram representados como dotados de uma origem, ora advindos de uma "herança africana", ora constituídos em terras brasileiras, sob o signo da linearidade. Veremos a seguir como essas ideias puderam ser mais bem observadas a partir das comparações dos maracatus com outras manifestações culturais assemelhadas.

\section{Origens e tradição: discutindo novos conceitos}

Pode-se considerar como algo possível a ideia de que os construtores dos maracatus-nação tenham de fato se servido das inúmeras heranças legadas pelas festas de coroação dos reis do Congo, mas isso não implica em uma ligação direta entre ambos. Composições, cisões, adaptações, ressignificações, dentre vários termos, devem servir para mostrar que no meio desse caminho, outros tantos eram possíveis. Se, por acaso, existe uma grande variedade de manifestações culturais e formas de expressão que são apontadas como originadas das festas de coroação dos reis de Congo, é bem possível que tenham exercido influências mútuas, corroborando para a tese de que a busca pela origem e exatidão do surgimento dos maracatus-nação constitui algo impossível de ser estabelecido ${ }^{8}$. As origens dos maracatus fazem parte das constantes bricolagens praticadas por homens e mulheres no quotidiano.

Além disso, há outras formas de expressão e manifestações culturais que permitem pensar em vários pontos de origens, e que possivelmente confluíram em uma razoável variedade de tipos de maracatus. A própria existência, hoje, das cambindas e dos congos, além das aruendas de Goiana, sugere a diversidade de formatos que precederam

\footnotetext{
${ }^{8}$ Sobre os reis de Congo, ver: SOUZA, 2002.
} 
às atuais nações de maracatu ${ }^{9}$. Ainda existem outras manifestações culturais similares aos maracatus, se levarmos em conta os grupos que sobrevivem a duras penas, a exemplo das pretinhas do Congo de Goiana (sede) e de Carne de Vaca. ${ }^{10}$

Pode-se afirmar que há grandes diferenças entre os próprios maracatus, mesmo quando tentamos estabelecer as semelhanças dentro dos dois grupos: nação ou baque virado e orquestra ou rural. Nada é mais diferente entre os maracatus de orquestra do que o terno do maracatu Cruzeiro do Forte e o do Cambindinha de Arassoiaba, e muito há de distante entre os batuques do Estrela Brilhante de Igarassu e os maracatus Gato Preto, Baque Forte e Encanto da Alegria. Aliás, mesmo entre esses últimos, as diferenças nos toques são perceptíveis até para os ouvidos dos não iniciados entre as sonoridades percussivas dos maracatus-nação ${ }^{11}$.

Enfim, o que se pode concluir da discussão sobre a origem dos maracatus é a ideia, construída pela maioria dos estudiosos, folcloristas e memorialistas, de uma história linear que vem desde as festas de coroação dos reis do Congo e que, por conseguinte, retira dos sujeitos, daqueles que fazem essas práticas culturais, as composições, escolhas, ressignificações, e a própria capacidade do fazer histórico.

A relação entre os maracatus-nação e os Reis do Congo, balizada numa ideia de origem, cai por terra quando se observa terem sido ambos contemporâneos durante muitos anos no século XIX (MAC CORD, 2001, p. 215-220). Percebe-se também que há uma significativa quantidade de indícios que nos mostram a contemporaneidade dos maracatus aos reinados de Congo, principalmente na segunda metade do século XIX. Leonardo Dantas, folclorista recifense, ao escrever um artigo sobre a instituição dos reis

\footnotetext{
9 Sobre as cambindas, ver: TRIGUEIRO; BENJAMIN, 1978. Sobre os Congos, ver: BENJAMIN, 1977. Sobre as aruendas de Goiana, ver: OLIVEIRA, 1949; ARAÚJO, 1967, p. 304. Alguns congos e cambindas foram gravados e estão no Cd Acervo FUNARTE. Documento do folclore brasileiro, v. 01, Instituto Cultural Itaú / FUNARTE ATR32017.

${ }^{10}$ Sobre as Pretinhas do Congo, ver LIMA, 2005. Goiana é a última cidade da região metropolitana do Recife, localizada no seu extremo norte. Está situada a sessenta e dois quilômetros do Recife. Carne de Vaca é um distrito de Goiana. Está situada a sessenta e sete quilômetros do Recife. É famosa por ter uma das mais belas praias da região norte de Pernambuco. $O$ acesso a Goiana é feito através da BR-101, que atualmente tem grande parte do seu trecho duplicado. Possui, atualmente, cerca de oitenta mil habitantes. $\mathrm{O}$ acesso a Carne de Vaca ocorre através da BR-101, e depois pela PE-049.

${ }^{11}$ Discuto sobre os dois tipos de sotaque existentes entre os maracatus, em: LIMA, 2014.
} 
de Congo, nos faz perceber que os maracatus foram contemporâneos e com os "soberanos do Congo" travou disputas, conforme se pode observar no trecho abaixo:

Na sessão extraordinária da Câmara Municipal do Recife em 28 de abril de 1851, esta mandou transmitir ao desembargador Chefe de Polícia "uma petição do preto africano Antonio de Oliveira, intitulado Rei do Congo, queixando-se de outro que, sem lhe prestar obediência, tem reunido os de sua nação para folguedos públicos, a fim de que o mesmo desembargador providenciasse em sentido de desaparecer semelhantes reuniões, chamadas vulgarmente de Maracatus, pelas conseqüências desagradáveis que delas podem resultar. (SILVA, 1988b, p. 35)

Faz-se necessário, entretanto, chamar a atenção para o fato de que não sabemos como eram esses maracatus que existiram no século XIX, devido à precariedade de descrições existentes, assim como não há muitas informações que permitam perceber o grau de diversidade existente no seio das coroações dos reis do Congo. Entretanto, o trecho acima nos permite observar a complexa relação existente entre essas manifestações. Veremos, a seguir, mais questões que apenas reforçam essa compreensão de manifestações culturais dinâmicas e complexas.

\section{Tradição: folcloristas versus práticas do quotidiano}

A discussão em torno da ideia de tradição não pode ser dissociada das práticas do quotidiano de quem a vivencia. Imaginar que um costume ou prática é mantido sob a força da repetição pura e simples pode afastar interpretações sensatas sobre os processos de adaptação da "tradição" às muitas dificuldades que o dia a dia coloca para homens e mulheres que vivem em uma sociedade bastante complexa. Também os torna desprovidos da construção de táticas e estratégias para a legitimação de interesses que vão desde a busca de espaços na sociedade, como de enfrentamento com possíveis concorrentes que por ventura disputem o mesmo objetivo. Sim, prezado leitor, os maracatuzeiros e seus maracatus disputam espaços entre si! Nesse aspecto, o conceito de tradição pode ser visto como um recurso que é usado constantemente pelos maracatuzeiros para legitimar suas práticas e, ao mesmo tempo, manterem seus costumes em meio a uma sociedade complexa e veloz em mudanças. A tradição, enquanto conceito, não pode ser vista distante de quem a faz, imutável e cristalizada 
para servir de guia aos homens e mulheres que fazem e refazem os seus costumes, adaptando-os em meio às dificuldades.

Assim sendo, não se deve perceber os maracatus como imutáveis e resultantes de uma história linear, com um começo, meio e fim. Apesar de que a imutabilidade desses grupos foi afirmada por Katarina Real, a partir da célebre descrição do maracatu Cambinda Velha, feita por Pereira da Costa, conforme indiquei anteriormente (REAL, 1990, p. 59). Essa ideia de que os maracatus em nada mudaram ao longo de cem anos deve ser pensada com mais vagar, apesar de a questão não estar entre os objetivos a serem discutidos neste artigo. Entretanto, ao afirmar que os maracatus permanecem íntegros, sem sinais da mudança, resta salientar que o discurso da autenticidade, assim como da ideia de tradição, não poderia levar a conclusões diferentes para quem deseja “manter” uma prática como legítima, ou, por que não dizer, “autêntica”.

O fazer e o refazer das práticas e costumes culturais é algo típico da ação humana, conforme Aristóteles (1996). Nada se mantém com base na repetição, muito menos uma prática cultural tão complexa como o maracatu. A discussão em torno das "origens" dos maracatus deve, doravante, cogitar outras possibilidades que não foram percebidas pelos estudiosos.

\section{Aruendas, pretinhas do Congo, Cambindas: manifestações culturais semelhantes aos maracatus}

Os maracatus-nação da atualidade trazem consigo diversas marcas, que indicam a fragilidade das ideias subjacentes a uma linearidade, e do consenso em torno de suas origens. Muitas são as diferenças entre um maracatu e outro: o toque, a maneira como se costuram as fantasias, a forma de cantar, as filiações religiosas que estabelecem, as regras internas de cada um... Muitas também são as semelhanças que nos permitem dizer que todos são maracatus, entretanto, não se pode afirmar que "é tudo a mesma coisa" ou que "são iguais um ao outro" (LIMA, 2004). Além das diferenças, chamam a atenção os aspectos relacionados às semelhanças existentes com outras manifestações culturais, a exemplo das aruendas, cambindas e pretinhas do Congo. 
No tocante às aruendas, infelizmente não dispomos das condições que tiveram os estudiosos de anos anteriores para fazer uma descrição minuciosa dessa manifestação cultural, ou sequer tirar fotos da mesma, uma vez que as aruendas não existem além das memórias de seus antigos praticantes, ou de registros fotográficos. Na revista Contraponto há uma excelente descrição e algumas fotos mostrando como eram e que instrumentos usavam, assim como por onde desfilavam na cidade de Goiana, e os nomes que os seus integrantes atribuíam a cada grupo (OLIVEIRA, 1949). Guerra Peixe, em 1980, utilizou-se dessa matéria para mostrar as semelhanças entre essa manifestação cultural e os maracatus, assim como discorreu sobre algumas das suas particularidades (PEIXE, 1980). Araújo (1967) também entabulou algumas questões sobre as aruendas, mostrando pontos como o fato de que eram os homens que cumpriam com o papel de dama do paço, ao contrário dos maracatus em que tal posto, na atualidade, é exclusivamente feminino. Em suma, mesmo com diferenças, as aruendas possuíam semelhanças com os maracatus-nação, a começar pelos nomes dos grupos (em alguns casos eram homônimos de maracatus que já haviam desfilado no Recife em anos anteriores); as letras das toadas, e sua estrutura melódica; além do vestuário e personagens (LIMA, 2005). Nas aruendas utilizavam-se maracás, instrumentos também usados no auto das pretinhas do Congo. Os instrumentos musicais das aruendas eram bombos, gonguê, tarol e maracás, ao passo que nos maracatus-nação utiliza-se atualmente um instrumento denominado por mineiro, que possui função semelhante ao maracá no corpo instrumental do batuque. Neste último, conforme descrito no início do artigo, também se utilizam os instrumentos que foram citados como de uso nas aruendas.

Ainda sobre as aruendas, pode-se encontrar na Revista Contraponto a informação de um senhor chamado Francisco Roxo, considerado como o último sobrevivente da Aruenda laiá Pequena, de que existiam vários grupos análogos, e que cada um possuía um nome próprio. Estes, em sua maioria, nos remetem aos maracatus que existiam no Recife, cujos nomes eram semelhantes. Na revista são citadas pelo Sr. Francisco Roxo as seguintes aruendas: Cambinda do Porto, Cambinda Brilhante, Centro Pequeno, Oriente Pequeno, Lagoa em França e laiá Pequena. Grupos homônimos aos maracatus recifenses, conforme as listas de licença divulgadas pela Repartição Central de Polícia nos carnavais 
dos últimos anos do século XIX (LIMA, 2005). Outra senhora, também entrevistada pelos repórteres dessa revista, relatou a existência de outras aruendas: Dois de Ouro, laiá Menina e mais as que foram citadas por Francisco Roxo. Em jornais que foram publicados no Recife, entre os anos de 1886 e 1926, figuram diversos maracatus, dos quais citamos Cambinda do Porto, Centro Pequeno, Oriente Pequeno e Dois de Ouro dentre outros. Vale ressaltar que a informante da revista, que não teve seu nome divulgado, afirmou que as aruendas eram “do tempo da monarquia”. Assim, é possível que tenha havido algum tipo de contato entre os integrantes das aruendas e os maracatuzeiros do Recife, se pensarmos na relação das datas existentes tanto entre os maracatus como para as aruendas.

E mais uma vez é possível indagar sobre a suposta origem linear dos maracatus a partir das festas de coroação dos reis e rainhas do Congo: sendo as aruendas uma manifestação cultural assemelhada aos maracatus, qual prática foi criada primeiro? Essa questão ganha relevos maiores de complexidade com outras manifestações culturais que veremos a seguir.

\section{Pretinhas do Congo}

Em Goiana também é possível encontrar uma manifestação cultural conhecida por Pretinhas do Congo. Existem atualmente dois grupos, ambos disputando entre si o título de "mais antigo", sendo um na sede do município, no bairro intitulado por Baldo do Rio, e o outro no paradisíaco lugarejo de Carne de Vaca. ${ }^{12}$ Os discursos enunciados por Dona Carminha e Mestre Val indicam que os praticantes dos grupos de Pretinhas do Congo não são simples “mantenedores de tradições". A disputa pela condição de mais antigo é facilmente compreensível nos seus discursos, sobretudo se levarmos em conta o fato de que em meio às disputas por recursos, a condição de “mais antigo” pode agregar outros

\footnotetext{
${ }^{12}$ Baldo do Rio fica próximo ao Rio Goiana. Em geral, é atingido pelas enchentes em momentos de fortes chuvas. O bairro guarda consigo várias manifestações culturais que integram o patrimônio imaterial da cidade, a exemplo da Procissão de São Pedro e de alguns caboclinhos. O grupo desta manifestação, Pretinhas do Congo, era articulado pelo saudoso Heleno, falecido no início dos anos 2000, e atualmente é dirigido por seu irmão, Mestre Val. O grupo de Carne de Vaca era articulado por Dona Carminha, falecida em pleno carnaval, no ano de 2016. Atualmente o grupo é mantido por suas netas e familiares.
} 
sentidos, a exemplo de "maior autenticidade" e, por conseguinte, legitimidade. Essas questões podem ser observadas no âmbito de outras manifestações culturais.

Segundo Roberto Benjamin (2001), as pretinhas do Congo foram por ele observadas pela primeira vez em 1977. O grupo era dirigido por Heleno, já falecido e que era irmão de Mestre Val, o atual dirigente. Em Carne de Vaca, o grupo é quase que predominantemente composto por mulheres, diferentemente do co-irmão, localizado em Baldo do Rio. Neste último há significativa presença masculina, ao passo que no grupo de Carne de Vaca as atividades eram dirigidas por Dona Carminha. Roberto Benjamin afirma que essa manifestação cultural é também "originária das festas de coroação dos reis e rainhas do Congo" (BENJAMIN 2001, p. 09), deixando implícito tratar-se de uma manifestação com muitas semelhanças aos maracatus-nação. Não creio que haja meios que permitam discutir a "origem" das pretinhas do Congo, pelas mesmas razões elencadas acima, para os maracatus-nação. Dona Carminha, dirigente do grupo de Carne de Vaca, em uma das entrevistas que me concedeu, indicou que no passado havia desfilado em uma aruenda. Essa questão permite especular a hipótese de que talvez as pretinhas do Congo tenham sido as sucedâneas das antigas aruendas, e com elas tido trocas e empréstimos de práticas, indicando a complexidade existente no seio das manifestações culturais.

As músicas das Pretinhas do Congo são denominadas de "jornadas" e a que gravei, em Carne de Vaca, tem a seguinte letra: “mas o povo assim dizia que as Pretinhas não saíam, as Pretinhas tá na rua com prazer e alegria"; no maracatu Nação Indiano, a letra aparece da seguinte maneira: "mas o povo assim dizia, que Indiano não saía, o Indiano está na rua com prazer e alegria”. Interessante ressaltar que a toada cantada pelo Indiano não constitui fenômeno isolado, pois outros maracatus-nação também utilizam a mesma letra, adaptando-a ao seu modo e estilo. Podemos considerar que o uso simultâneo de tal letra pode ter sido provocado, talvez, pelo contato que existiu de alguma maneira entre os integrantes das pretinhas do Congo de Goiana com os maracatuzeiros. Ou mesmo terem sido essas letras de uso compartilhado pelos participantes das aruendas. É possível que o contato tenha ocorrido ainda na época das aruendas, visto que há diversas semelhanças entre a manifestação cultural e os maracatus-nação. 


\section{Cambindas}

Sobre as cambindas, há diversas indagações e poucas respostas, sobretudo no que diz respeito à grande diversidade que existe atualmente entre os grupos dessa manifestação cultural. Roberto Benjamin afirma que existem cambindas nos municípios de Ribeirão, São Bento do Una, Pesqueira e Triunfo. Ao discorrer sobre as diferenças existentes entre os grupos, o estudioso afirmou:

Pelas características de suas músicas e de suas danças, as cambindas se diferenciam entre si e não apresentam semelhanças com as formas de maracatu como nós conhecemos hoje, nem o maracatu-nação-africana (de baque virado), nem o maracatu rural (de orquestra). Talvez encontrem semelhanças com outro tipo de maracatu desaparecido no Recife, ou que tenham se formado diretamente dos folguedos de reis negros, que integraram as festas de Nossa Senhora do Rosário. Poderiam ter, assim, uma origem comum com os maracatus. (BENJAMIN, 2001, p. 08)

Os grupos de cambindas, na visão de Roberto Benjamin, não possuem semelhanças com os maracatus-nação atuais. Entretanto, não se pode deixar de salientar que as cambindas possuem traços parecidos com os maracatus de orquestra, a começar pelo fato de que nessa manifestação cultural desfilam homens travestidos de mulheres, aspecto que se repetia nos grupos de maracatus (de orquestra) mais afastados das zonas urbanas (BENJAMIN, 1982). Aliás, ainda hoje alguns grupos apresentam personagens que são feitos por homens trajando roupas femininas. Assim sendo, entre as aruendas, maracatus de orquestra e cambindas há essa semelhança, e que pode ser reforçada se imaginarmos que nos antigos grupos de maracatus-nação do Recife também existiam homens travestidos de mulheres. Rodrigues de Carvalho, no início do século, observou e descreveu um grupo que afirmou ser um maracatu:

Maracatús: são foliões caracterisados (sic) de negro, vestidos, de calças e jalecos, outros de saias e camisas de mulher, fingindo negras bahianas, tocando maracás e dançando loucamente pelas ruas. (CARVALHO, 1928, p. 23)

Essa descrição pode ser encontrada numa pequena nota de rodapé do livro Cancioneiro do Norte, publicado pela primeira vez no ano de 1903. A descrição do que Rodrigues de Carvalho denomina de maracatu, diverge frontalmente do tipo que foi 
descrito por Pereira da Costa também no início do século passado. Entretanto, tal questão nos remete a dúvidas, uma vez que Rodrigues de Carvalho, por mais que não fosse um maracatuzeiro, também não era um homem que desconhecia tudo o que se referia às manifestações culturais ${ }^{13}$. Talvez existissem maracatus no Recife que possuíssem a prática de homens desfilando com roupas femininas. Ao escrever sobre as cambindas, Oneyda Alvarenga destacou a semelhança destas com os maracatus (ALVARENGA, 1950). Não há como saber qual o maracatu que se assemelhava com as cambindas, no olhar de Oneyda, mas suspeito que a indicação aponte para a complexidade dessas manifestações culturais. A questão nos remete para as filiações de diferentes manifestações culturais ainda hoje existentes, atuantes (e que foram descritas ora como "sobrevivências", ora como "descaracterizações") com os maracatus-nação recifenses. Estes, por sinal, constituem conteúdo imenso de pluralidades, e um estudo que levante os diferentes formatos, que por ventura tenham existido, poderá indicar mais luzes para o debate que ainda está por ser feito. Vale ressaltar que a descrição célebre, feita por Pereira da Costa, pode ser tomada como pista para pensar com maior minudência o enigma das manifestações culturais. ${ }^{14}$

Sobre os maracatus dos últimos anos do século XIX e dos primeiros do XX, quase nada existe em termos de descrições que não seja a já célebre, feita por Pereira da Costa:

Um cortejo régio, que desfila com toda a solenidade inerente à realeza, e revestido, portanto, de galas e opulências. Rompe o préstito um estandarte ladeado por arqueiros, seguindo-se em alas dois cordões de mulheres lindamente ataviadas, com os seus turbantes ornados de fitas de cores variegadas, espelhinhos e outros enfeites, figurando no meio desses cordões vários personagens, entre os quais os que conduzem os fetiches religiosos - um galo de madeira, um jacaré empalhado e uma boneca de vestes brancas com manto azul; - e logo após, formados em linhas, figuram os dignitários da corte, fechando o préstito o rei e a rainha. Estes dois personagens, ostentando as insígnias da realeza, com coroas, cetros e compridos mantos sustidos por caudatários, marcham sob uma grande umbela e guardados por arqueiros. No coice vem os instrumentos: tambores, buzinas e outros de feição africana, que acompanham os cantos de marcha e dança diversas com um estrépito horrível. (COSTA, 1974, p. 215)

\footnotetext{
${ }^{13}$ Sobre Rodrigues de Carvalho, ver: MARQUES, 2013.

${ }^{14}$ Além das cambindas, aruendas, congos e pretinhas do Congo, pode-se afirmar existirem semelhanças destes com os maracatus-nação e com os grupos congêneres, nomeados por maracatus de orquestra. Sobre estes, ver: BENJAMIN, 1976.
} 
Essa é a única fonte descritiva que restou sobre como era o Cambinda Velha, maracatu que serviu de objeto para a referida observação. Não se sabe se a mesma dava conta de um modelo da manifestação, ou se existiam outros formatos de maracatus desfilando pelo Recife da época. Como um contraponto ao que viu e escreveu Pereira da Costa, Rodrigues de Carvalho apontou outras características, conforme indiquei acima, revelando os indícios de que talvez houvesse outros tipos de maracatus. A descrição feita por Rodrigues de Carvalho mostra uma abrupta diferença do tipo de maracatu que ele descreveu, quando comparado com o que foi observado por Pereira da Costa. É óbvio que diante das duas descrições, uma questão pode ser formulada: o que se considerava como maracatu no final do século XIX e início do XX? Tanto Clarissa Nunes Maia, como Leonardo Dantas Silva, permitem conjecturar que a palavra "maracatu" referia-se a ajuntamentos de "negros" associados a batuques e danças (MAIA, 1995; SILVA, 2002). Gradativamente, ao longo das últimas décadas do século XIX, a palavra "maracatu" foi se associando a um tipo específico de manifestação cultural, que coincide com a descrição feita por Pereira da Costa. O que não quer dizer que houvesse unanimidade quanto à descrição.

Outra questão que traz dificuldades em relação às pesquisas sobre como eram os maracatus nos primeiros anos do século XX, refere-se à notícia publicada no Jornal do Recife de 1911, que informa o nome das agremiações que iriam desfilar pelas ruas da capital pernambucana no carnaval daquele ano, bem como os seus respectivos endereços e diretores. Tal notícia nada teria de estranha, se não indicasse que os maracatus eram dotados de instrumentos de corda, e que essa informação se referia apenas aos grupos denominados de maracatus, excluindo os demais que não foram caracterizados como tal. 15 Desse modo, quando dirigimos o olhar para os maracatus do passado, tendo como parâmetros as descrições em questão, não há como responder com certeza, como eram esses grupos, quais instrumentos usavam, quem e quantos eram, e quando/onde desfilavam.

\footnotetext{
15 Jornal do Recife, sexta feira, 24/02/1911, p. 01 e domingo, 26/02/1911, p. 01. A notícia do jornal, do dia 24/02, era esta: “... Centro Pequeno (diretor: Manoel Fernandes de Souza, sede rua do socego, n 18. Instrumentos de corda), Porto Rico Pequeno (diretor Manoel Vieira Pessoa, sede rua Imperial. Instrumentos de cordas), Centro Grande (diretor Antonio Lins de Mello, sede rua do Sapoti (Pombal). Instrumentos de corda.), Cambinda Elephante (sede, Cajueiro 7. Instrumentos de cordas.) e Porto Rico Braço Cutello (diretor; Francisco Florentino da Rocha, sede Quadro Joaquim da Rocha (São José), instrumentos de corda)..."
} 


\section{Conclusão}

Ao discorrer sobre o debate em torno das origens dos maracatus, feito pelos estudiosos citados ao longo do artigo, destaquei o consenso existente entre eles em torno da suposta origem dos maracatus, decorrente das festas de coroação dos reis e rainhas do Congo. Acredito, no entanto, que a ideia de origem, apontando para uma história linear, não se sustenta mediante uma forte pesquisa documental e uma observação das descrições de várias manifestações culturais que apresentam muitas semelhanças entre si e com os maracatus-nação. Os maracatus, a meu ver, se constituem numa construção inacabada com contribuições diversas de homens e mulheres em um processo dinâmico. Daí a minha afirmação de que é praticamente impossível perceber a origem, ou, como diria Guerra Peixe, o momento exato do surgimento dos maracatus pelo fato de estarmos discutindo sobre práticas e costumes humanos, fruto do quotidiano e como tal, irremediavelmente perdidos no tempo e no espaço.

Quanto ao aspecto da linearidade dos maracatus com as festas de coroação dos reis e rainhas do Congo, tal relação de origem fica bastante abalada quando se observa que ambos foram contemporâneos durante muitos anos no século XIX (MACCORD, 2001). Percebe-se que há uma significativa quantidade de indícios que apontam a contemporaneidade dos maracatus aos reinados do Congo, principalmente na segunda metade do século XIX. Como indiquei mais acima, Leonardo Dantas mostra a existência de conflitos entre estes, o que sugere que a história possui maior complexidade, e que muito ainda se necessita pesquisar para melhor compreender as manifestações culturais ainda hoje existentes.

Enfim, imaginar outras possibilidades para o estudo dessas manifestações culturais ainda está em questão. Creio que as novas gerações de historiadores, munidas de outros repertórios conceituais e formas diversas de compreensão da História, poderão contribuir com a sequência deste processo. Com a palavra, o futuro... 


\section{Referências}

ALMEIDA, Renato. História da música brasileira. Rio de Janeiro: F. Briguiet \$ Comp, 1942.

ALMEIDA, Renato. Vivência e projeção do folclore. Rio de Janeiro: Livraria Agir, 1971.

ALVARENGA, Oneyda. Maracatu. In: Música Popular Brasileira. Porto Alegre: Globo, 1950.

ANDRADE, Mário. A calunga dos maracatus. In: Danças Dramáticas do Brasil. 2. tomo. Belo Horizonte / Brasília: Ed. Itatiaia / INL / Fundação Nacional Pró-memória, 1982.

ARAÚJO, Alceu Maynard. Folclore Nacional. Danças, recreação, música. v. II. 2.ed. São Paulo: Melhoramentos, 1967. [1964].

ARISTÓTELES. Poética. São Paulo: Nova Cultural, 1996, p. 31-60. Coleção Os pensadores.

ASSUNÇÃO, Luiz. O reino dos mestres: a tradição da jurema na umbanda nordestina. Rio de Janeiro: Pallas, 2006.

BASTIDE, Roger. Imagens do Nordeste místico em branco e preto. Rio de Janeiro: O cruzeiro, 1945.

BASTIDE, Roger. O candomblé da Bahia. São Paulo: Cia das Letras, 2001. [1958].

BENJAMIN, Roberto. Congos da Paraíba. Cadernos de Folclore: n.18. Rio de Janeiro: FUNARTE, 1977.

BENJAMIN, Roberto. Maracatus rurais de Pernambuco. In: PELLEGRINI FILHO, Américo (Org.). Antologia de folclore brasileiro. São Paulo: Edart, 1982.

BENJAMIN, Roberto. Maracatus rurais. Folclore: n. 12. Recife: FUNDAJ - Centro de Estudos Folclóricos, 1976.

BENJAMIN, Roberto. Maracatus, cambindas, pretinhas do Congo: herança negra diversificada no carnaval do interior. Suplemento Cultural do Diário Oficial do Estado de Pernambuco, Recife, . p. 7-9, fev. de 2001

BRANDÃO, Maria do Carmo; RIOS, Luis Felipe. O catimbó-jurema do Recife. In: PRANDI, Reginaldo (Org.). Encantaria brasileira. Rio de Janeiro: Pallas, 2001, p. 160-181.

BRANDÃO, Theo. Folguedos natalinos. Maceió: Depto de assuntos culturais, 1973. 
CARVALHO, Rodrigues. Cancioneiro do Norte. 2. ed. Parahyba do Norte: Typ. da Livraria São Paulo, 1928, $2^{\text {a }}$ ed. aumentada. [1903].

CASCUDO, Câmara. Vaqueiros e cantadores. Rio de Janeiro: Ediouro, 2000. [1939].

CASTRO, Celso. Evolucionismo cultural. Textos de Morgan, Tylor e Frazer. Rio de Janeiro: Jorge Zahar, 2005.

CHARTIER, Roger. À beira da falésia: a história entre certezas e inquietude. Porto Alegre: Ed. UFRGS, 2002.

CHARTIER, Roger. A história cultural entre práticas e representações. Lisboa: Difel, 1990.

COSTA, F. A. Pereira da. Folk-lore pernambucano: subsídios para a história da poesia popular em Pernambuco. Recife: Arquivo Público Estadual, 1974. [1908].

COSTA, G. B. A festa é de maracatu: cultura e performance no maracatu cearense (19802002). Dissertação (Mestrado em História) - Universidade Federal do Ceará, Fortaleza, 2009.

CRUZ, D. M. Maracatus no Ceará: sentidos e significados. Fortaleza: Editora da UFC, 2011.

CUNHA, Maria Clementina Pereira da. Ecos da folia: uma história social do carnaval carioca entre 1880 e 1920. São Paulo: Cia das Letras, 2001.

FOUCAULT, Michel. Microfísica do poder. Rio de Janeiro: Graal, 1984.

GONÇALVES, José Reginaldo Santos. A retórica da perda. Rio de Janeiro: Ed. UFRJ/ IPHAN, 2002.

LIMA, Ivaldo Marciano de França. Maracatu nação e grupos percussivos: diferenças, conceitos e Histórias. História: Questões \& Debates, Curitiba, n. 61, p. 303-328, jul./dez. 2014.

LIMA, Ivaldo Marciano de França. Maracatus e maracatuzeiros: desconstruindo certezas, batendo afayas e fazendo histórias. Recife, 1930-1945. Recife: Edições Bagaço, 2008.

LIMA, Ivaldo Marciano de França. Maracatus-nação: ressignificando velhas histórias. Recife: Bagaço, 2005.

LIMA, Ivaldo Marciano de França. Mas, o que é mesmo maracatu nação? Salvador:

EDUNEB, 2013. 
LIMA, Ivaldo Marciano de França. Os maracatus do Recife, as disputas e influências entre o fazer e o refazer dos toques: os casos do Cambinda Estrela, Porto Rico e Estrela Brilhante. In: ENCONTRO NACIONAL DA ABET, 2., 2004. Anais [...]. Salvador, em novembro de 2004 .

MAC CORD, Marcelo. O Rosário dos homens pretos de Santo Antônio: alianças e conflitos na história social do Recife, 1848 - 1872. Dissertação (Mestrado em História) - Programa de Pós-Graduação em História, UNICAMP, Campinas, 2001.

MAGALHÃES, Basílio. A origem do maracatu. Cultura política, Rio de Janeiro, ano 4, n. 45, out. de 1944.

MAGALHÃES, Basílio. O folclore no Brasil. Rio de Janeiro: Imprensa Nacional, 1939.

MAIA, Clarissa Nunes. Sambas, batuques, vozerias e farsas públicas: o controle social sobre os escravos em Pernambuco no século XIX (1850 - 1888). Dissertação (Mestrado em História) - Programa de Pós-Graduação em História, UFPE, Recife, 2001.

MARQUES, Ana Luiza de Vasconcelos. Canções e cores da nação brasileira: uma análise historiográfica das obras de Rodrigues de Carvalho (1903 - 1937). Dissertação (Mestrado em História) - Programa de Pós-Graduação em História, UFPB, João Pessoa, 2013.

MILITÃO, J. W. R. Maracatu Az de Ouro: 70 anos de memórias, loas e batuques. Fortaleza: Omni Editora, 2007.

MOTTA, Roberto. Religiões afro-recifenses: ensaios de classificação. Revista Antropológicas, Recife: UFPE, ano 2, v. 2, p. 11-34, 1997. Série religióes populares.

OLIVEIRA, Waldemar. Outro bailado típico de Goiana: a aruenda. Contraponto, Recife, ano 4, n. 11, dez. 1949.

PEIXE, Guerra. Maracatus do Recife. 2.ed. Recife: Prefeitura da Cidade do Recife/ Irmãos Vitale, 1980. [1955].

REAL, Katarina. Eudes o rei do maracatu. Recife: FUNDAJ/ Ed. Massangana, 2001.

REAL, Katarina. O folclore no carnaval do Recife. 2.ed. Recife: Fundação Joaquim Nabuco, - Ed. Massangana, 1990. [1967].

ROCHA, Everardo. O que é mito. São Paulo: Brasiliense, 1996. 
SALLES, Sandro Guimarães de. À sombra da jurema encantada: mestres juremeiros na umbanda de Alhandra. Recife: Editora da UFPE, 2010.

SALLES, Sandro Guimarães de. À sombra da jurema: a tradição dos mestres juremeiros na umbanda de Alhandra. Anthropólogicas, Recife: UFPE, ano 08, v. 15, p. 99-122, 2004.

SILVA, Ana Cláudia. Vamos maracatucá!!!: um estudo sobre os maracatus cearenses. Dissertação (Mestrado em Antropologia) - Programa de Pós-Graduação em Antropologia, Universidade Federal de Pernambuco, Recife, 2004.

SILVA, Leonardo Dantas da. A calunga de Angola nos maracatus do Recife. In: SILVA, Leonardo Dantas da. Estudos sobre a escravidão negra. v.2. Recife: Ed. Massangana, 1988b, p. 13-53.

SILVA, Leonardo Dantas. A corte dos reis do congo e os maracatus do Recife. Notícia bibliográfica e histórica, Campinas, PUC, n. 184, p. 43-64, 2002.

SILVA, Leonardo Dantas. A instituição do Rei do congo e sua presença nos maracatus. In: SILVA, Leonardo Dantas (Org.). Estudos sobre a escravidão negra. Recife: FUNDAJ / Ed. Massangana, 1988a.

SOUZA, Marina de Mello e. Reis negros no Brasil escravista: história da festa de coroação de rei de Congo. Belo Horizonte: Ed. UFMG, 2002.

TRIGUEIRO, Osvaldo Meira; BENJAMIN, Roberto. Cambindas da Paraíba. Cadernos de Folclore: n. 26. Rio de Janeiro: FUNARTE, 1978.

VANDEZANDE, René. Catimbó: pesquisa exploratória sobre uma forma nordestina de religião mediúnica. Dissertação (Mestrado em Sociologia) - Programa de Pós-Graduação em Sociologia, Universidade Federal de Pernambuco, Recife, 1975.

VILHENA, Luís Rodolfo. Projeto e missão: o movimento folclórico brasileiro (1947-1964). Rio de Janeiro: Funarte, 1997. 
Recebido em 14/03/2018 Aprovado em 21/03/2019

Universidade do Estado de Santa Catarina - UDESC Programa de Pós-Graduação em História - PPGH Revista Tempo e Argumento Volume 11 - Número 27 - Ano 2019 tempoeargumento@gmail.com 